\title{
Neuroprotective effects of midazolam on focal cerebral ischemia in rats through anti-apoptotic mechanisms
}

\author{
HANG YU ${ }^{1}$, XIAOZHI WANG ${ }^{1}$, FUXIN KANG $^{1}$, ZHILE CHEN $^{1}$, YUNXIA MENG $^{1}$ and MINGMING DAI ${ }^{2}$ \\ ${ }^{1}$ Intensive Care Unit; ${ }^{2}$ Department of Internal Neurology, The Second Affiliated Hospital of Hainan Medical University, \\ Haikou, Hainan 570311, P.R. China
}

Received September 3, 2017; Accepted February 2, 2018

DOI: $10.3892 /$ ijmm.2018.3973

\begin{abstract}
Stroke is a cerebrovascular circulatory disorder and its high mortality rate represents a prominent threat to human health. Subsequent apoptosis and cytotoxicity are the main causes underlying the poor prognosis. Midazolam (MDZ) is a benzodiazepine drug that is clinically used during surgical procedures and for the treatment of insomnia, with a potential ability to treat stroke. The protective effect of MDZ was investigated on glutamate-induced cortical neuronal injuries in vitro and transient middle cerebral artery occlusion (tMCAO) rat models in vivo. Western blot analysis and semi quantitative RT-PCR were used to evaluate the potential underlying mechanisms. In vitro studies revealed that MDZ regulated apoptosis-associated gene expression and inhibited lactate dehydrogenase $(\mathrm{LDH})$ release, protecting against neuronal damage. In vivo studies revealed that MDZ reduced LDH-induced neuronal damage by reducing LDH release from the peripheral blood, and brain tissue staining revealed that MDZ protected neurons during tMCAO. MDZ protected neurons under an ischemic environment by inhibiting $\mathrm{LDH}$ release and regulating apoptosis-associated gene expression to reduce cytotoxicity and apoptosis. These results provide a reliable basis for further studies on the effect of MDZ, to improve the prognosis of cerebral infarction.
\end{abstract}

\section{Introduction}

Stroke, especially ischemic stroke, is a disorder that results in high rates of disability and mortality $(1,2)$. High incidence and recurrence rates are also characteristics, resulting in a serious threat to human health (3). The poor prognosis is partially due to the subsequent release of cytotoxic factors and the resultant

Correspondence to: Professor Mingming Dai, Department of Internal Neurology, The Second Affiliated Hospital of Hainan Medical University, 48 Baishui Pond Road, Haikou, Hainan 570311, P.R. China

E-mail: 18580701104@163.com

Key words: cerebral infarction, neuron, cytotoxicity, apoptosis, midazolam apoptosis (4-6). Apoptosis caused by focal ischemia of a short duration (30-60 $\mathrm{min}$ ) is a prominent feature of the ischemic stroke region and penumbra border region, where neuronal degeneration and necrosis occur $(7,8)$. Thus, the development of anti-apoptotic drugs able to improve the prognosis of stroke is necessary (9).

Previous studies have demonstrated that B cell lymphoma-2 (Bcl-2) and caspase-3 are involved in apoptosis regulation (9-11). Bcl-2 overexpression inhibits the activation of caspase- 3 and subsequent apoptosis (10). Caspase-3 is the most important terminal cleavage enzyme in the process of apoptosis, and serves a major function in the induction of apoptosis $(10,12)$. P53 also increases the expression of BCL2 associated X, apoptosis regulator (Bax), which is an apoptosis promoter belonging to the BCL-2 gene family, and its overexpression antagonizes Bcl-2 (13). Bcl-2 downregulation also promotes apoptosis (14). Thus, Bcl-2/Bax, caspase-3 and p53 may serve an important function in apoptosis, including neuronal apoptosis.

Glutamate (GLU) is an excitatory neurotransmitter in the central nervous system, but its excessive accumulation in the extracellular matrix may result in ischemic brain damage (15). Lactate dehydrogenase (LDH) is present in the cytoplasm of normal cells and is released when the cells are damaged. Thus, its activity reflects the degree of cell damage and cytotoxicity (16).

Midazolam (MDZ) is a typical benzodiazepine drug with several functions, including anti-anxiety, sedation and hypnosis. Intramuscular or intravenous injection produces short anterograde memory loss, since the drug is capable of quickly crossing the blood-brain barrier $(17,18)$. MDZ does not appear to induce drug resistance, abstinence symptoms or rebound (17). MDZ has previously been demonstrated to inhibit caspase-3 activation (19). Furthermore, MDZ inhibits the apoptosis of astrocytes induced by oxygen and glucose deprivation (20). Therefore, MDZ may exert a protective effect on neuronal apoptosis induced by cerebral ischemia.

Thus, the hypothesis of the present study was that MDZ regulates the expression of apoptosis-associated genes to inhibit apoptosis, together with the inhibition of cytotoxicity to protect neurons and confer recovery-promoting effects.

To validate this hypothesis, GLU-induced neuronal injury was performed in vitro. LDH release and the expression of apoptosis-associated genes were measured to evaluate cytotoxicity and apoptosis. In the constructed transient middle 
cerebral artery occlusion (tMCAO) animal model, neuronal protection was evaluated by an LDH release assay and tissue staining.

\section{Materials and methods}

Neuron isolation and culture. Neurons were obtained from 20 male Sprague Dawley rats (8-12 weeks old; weight, 300-500 g) purchased from the Animal Experimental Center of Hainan Medical University, The Second Affiliated Hospital (Haikou, China). Rats had free access to water and food and they were kept under the standard laboratory conditions $\left(22-25^{\circ} \mathrm{C} ; 65 \pm 5 \%\right.$ humidity; $12 \mathrm{~h}$ light/dark cycle). Following sacrifice, the brain was carefully removed from the skull and placed on ice. The meninges were removed under a dissecting light microscope and the cortical tissue was collected, placed in a centrifuge tube, mixed with $0.125 \%$ trypsin (Beyotime Institute of Biotechnology, Haimen, China) and digested at $37^{\circ} \mathrm{C}$ for $30 \mathrm{~min}$. Dulbecco's modified Eagle's medium (DMEM; Invitrogen; Thermo Fisher Scientific, Inc., Waltham, MA, USA) containing 5\% fetal bovine serum (FBS; Gibco; Thermo Fisher Scientific, Inc.) was added to the digested tissue and the mixture was carefully pipetted. Then, the tube was left to stand at $37^{\circ} \mathrm{C}$. Fluid without large particles was transferred into another centrifuge tube and the cell suspension was carefully pipetted several times to obtain a suspension with no visible tissue. Fluid was pipetted in a six-well plate and the supernatant was transferred to another plate containing 5\% FBS, 2\% B27 (Gibco; Thermo Fisher Scientific, Inc.) and neurobasal medium (Gibco; Thermo Fisher Scientific, Inc.) after $2 \mathrm{~h}(21,22)$.

MTT assay. Neuron viability was detected by MTT assay. A total of $10^{4}$ neurons/well were seeded in 96-well plates containing $200 \mu 1$ DMEM with 10\% FBS to evaluate neuron proliferation at different concentrations of MDZ (Shanghai Guyan Biological Technology Co., Ltd., Shanghai, China) and GLU (Sigma-Aldrich; Merck KGaA, Darmstadt, Germany). MTT was added and incubated for $4 \mathrm{~h}$ at $37^{\circ} \mathrm{C}$ (Cytotoxicity Assay kit; Beyotime Institute of Biotechnology). DMSO (Sigma-Aldrich; Merck KGaA) was used to dissolve the formazan crystals. Obtical density was measured at a wavelength of $570 \mathrm{~nm}$. Neurons without MDZ or GLU treatment represented control group 1, while groups 2-7 were simultaneously treated with GLU (final concentration, $100 \mu \mathrm{M}$ ) and $\mathrm{MDZ}$ at concentrations of $0,0.1,0.3,0.5,0.7$ or $0.9 \mathrm{mg} / \mathrm{l}$ at $37^{\circ} \mathrm{C}$ for $4 \mathrm{~h}(23,24)$

$L D H$ release assay. Neurons were seeded as described in the previous paragraph, and incubated with GLU and MDZ at different concentrations as aforementioned. LDH was measured using an LDH assay kit (Nanjing KeyGen Biotech Co., Ltd., Nanjing, China) according to the manufacturer's protocol $(16,25)$.

Apoptosis evaluation by flow cytometry. Neurons were seeded as previously described and incubated with $0.7 \mathrm{mM}$ MDZ and GLU (final concentration, $100 \mu \mathrm{M}$ ). In group 2, only GLU was added (final concentration, $100 \mu \mathrm{M}$ ), while the control group lacked any treatment. The medium was removed, neurons were washed with PBS and EGTA-free trypsin was added. When neurons were detached, PBS was added, and neurons were collected in a $15 \mathrm{ml}$ tube and centrifuged at $1,000 \mathrm{x}$ g for $3 \mathrm{~min}$ at room temperature. Next, neurons were washed with PBS and centrifuged at 1,000 $\mathrm{x}$ g for $3 \mathrm{~min}$ at room temperature. Annexin- $V$ from a Fluorescein Isothiocyanate-Annexin V Apoptosis Detection kit (BD Biosciences, San Jose, CA, USA) was used according to the manufacturer's protocol and apoptosis was measured by MoFlo Astrios EQ flow cytometry and corresponding Summit version 6.2 software was used to analyze the results (Beckman Coulter, Brea, CA, USA) $(26,27)$.

Western blot. Neurons were cultured in serum-free DMEM medium for $24 \mathrm{~h}$. NP40 cell lysis buffer (Gibco; Thermo Fisher Scientific, Inc.) was used to lyse neurons on ice for $5 \mathrm{~min}$, and sonication $(20-24 \mathrm{kHz})$ was used to further cell cleavage at $0^{\circ} \mathrm{C}$ (8 times within $2 \mathrm{~min}, 5 \mathrm{sec}$ each time and pauses of $10 \mathrm{sec}$ ). Cell debris was removed by centrifugation at $1,000 \mathrm{x} \mathrm{g}$ for $1 \mathrm{~min}$ at $0^{\circ} \mathrm{C}$ and total protein was obtained and detected by Bicinchoninic acid (BCA) method using BCA Protein Assay kit (Beyotime Institute of Biotechnology) according to the manufacturer's protocol.

Graded 4-15\% polyacrylamide gels were used (Bio-Rad Laboratories, Inc., Hercules, CA, USA) and $50 \mu \mathrm{g}$ protein were loaded per lane, followed by electrophoresis to separate the target proteins. Then, proteins were transferred onto Immobilin-P membranes (Sigma-Aldrich; Merck KGaA), and membranes were blocked by 5\% non-fat milk for $1 \mathrm{~h}$ at room temperature. Samples were incubated overnight with antibodies against Bcl-2 (cat. no. ab692; 1:500), Bax (cat. no. ab32503; 1:500), p53 (cat. no. ab26; 1:1,000), caspase-3 (cat. no. ab13585; 1:500) and GAPDH (cat. no. ab8245; 1:500) all from Abcam (Cambridge, MA, USA), diluted in 5\% skim milk powder. Following washing twice with PBS and Dulbecco's PBS, samples were treated with goat anti-mouse immunoglobulin G H\&L (cat. no. ab6785; 1:10,000; Sigma-Aldrich; Merck KGaA) and incubated at room temperature for $1 \mathrm{~h}$. Immunoreactive bands were cut and an Odyssey SA infrared imaging system (LI-COR Biosciences, Lincoln, NE, USA) was used to observe the results $(28,29)$.

Semi quantitative reverse transcription-polymerase chain reaction $(R T-P C R)$. Semi quantitative RT-PCR amplification was used to evaluate the expression of apoptotic genes with the A1250 Access RT-PCR system (Promega Corporation, Madison, WI, USA). Neurons were digested with 5\% trypsin (Beyotime Institute of Biotechnology) and divided into single cells under a light microscope. Then, cells were lysed with NP40 cell lysis buffer in PCR tubes for $2 \mathrm{~h}$ on ice. $\mathrm{MgSO}_{4}$ $(25 \mathrm{mM})$, nuclease-free water, dNTP mix, AMV/Tfl 5X Reaction Buffer, SuperScript ${ }^{\circledR}$ IV reverse transcriptase (all Invitrogen; Thermo Fisher Scientific, Inc.), and specific upstream and downstream primers for GAPDH, p53, caspase-3, $\mathrm{Bcl}-2$ and Bax were added to a $0.5 \mathrm{ml}$ reaction tube. The thermocycling conditions for the PCR were set according to the manufacturer's protocol of SuperScript ${ }^{\mathrm{TM}}$ One-Step RT-PCR System with Platinum ${ }^{\mathrm{TM}}$ Taq DNA Polymerase included in the Prime Script TM RT reagent kit (Invitrogen; Thermo Fisher Scientific, Inc.). PCR products were detected by $1.2 \%$ agar gel electrophoresis $(0.5 \mu \mathrm{g} / \mathrm{ml}$ ethidium bromide) and observed 
under ultra violet light, as previously described $(30,31)$. The results were analyzed by Quantity One software (version 4.62; Bio-Rad Laboratories, Inc.). The primers used were the following: GAPDH forward, 5'-ACCACAGTCCATGCCATC AC-3' and reverse, 5'-TCCACCACCCTGTTGCTGTA-3'; p53 forward, 5'-ACCTATGGAAACTACTTCCTGAAA-3' and reverse, 5'-CTGGCATTCTGGGAGCTTCA-3'; caspase-3 forward, 5'-TGGAACAAATGGACCTGTTGACC-3' and reverse; 5'-AGGACTCAAATTCTGTTGCCACC-3'; Bcl-2 forward, 5'-TTCTTTGAGTTCGGTGGGGTC-3' and reverse, 5'-TGCATATTTGTTTGGGGCAGG-3'; and Bax forward, 5'-TCCACCAAGAAGCTGAGCGAG-3' and reverse; 5'-GTC CAGCCCATGATGGTTCT-3'.

Animal model. All animal procedures followed the Guide for the Care and Use of Laboratory Animals (33) and were approved by the Institutional Clinical Experiments Committee of the Second Affiliated Hospital of Hainan Medical University (Haikou, China). Sprague Dawley rats (male, 3 months old, $300-500 \mathrm{~g}$ ) were randomly divided into 4 groups as follows ( $n=40 ; n=10$ in each group): Sham group, model group, MDZ ( $2 \mathrm{mg} / \mathrm{kg}$ ) group, and MDZ (5 mg/kg) group. Rats had free access to water and food and they were housed under stable conditions $\left(22-25^{\circ} \mathrm{C} ; 0.03 \% \mathrm{CO}_{2} ; 65 \pm 5 \%\right.$ humidity; $12 \mathrm{~h}$ light/dark cycle). Sodium pentobarbital $2.5 \%$ (36 mg/kg; Sigma-Aldrich; Merck KGaA) was used to anesthetize the rats. The common carotid artery, internal carotid artery and external carotid artery were isolated, while the wing palate artery and the cranial branches of the mentioned arteries were separated. Arterial clips were used to clamp the common carotid artery and the internal carotid artery. The distal end of the external carotid artery was ligated and cut. A 5-cm-long nylon filament (diameter, 0.24-0.28 mm) was then inserted into the middle cerebral artery for $2 \mathrm{~h}$. Sham-operated rats were subjected to the same surgical procedure as the rats from the tMCAO groups (34), except for the occlusion of the middle cerebral artery. Rats were treated with a sublingual intravenous injection of MDZ or the same volume of normal saline 10 min following ischemia $(34,35)$.

Tetrazolium chloride (TTC) staining and toluidine blue staining. A total of 24 and $72 \mathrm{~h}$ following tMCAO induction, rats were sacrificed under deep anesthesia induced by sodium pentobarbital injection. The number of animals used for each group was 10. Rats randomly selected from each group were used for TTC staining (Beyotime Institute of Biotechnology). Brains were carefully removed and cut into six 2.0-mm-thick coronal sections. Sections were stained with $2 \%$ TTC in normal saline for $30 \mathrm{~min}$ at $37^{\circ} \mathrm{C}$, and fixed in $4 \%$ paraformaldehyde solution overnight at $4^{\circ} \mathrm{C}(34)$.

Brain tissues were stained for $10 \mathrm{~min}$ at room temperature with $0.04 \% \mathrm{w} / \mathrm{v}$ toluidine blue in $0.1 \mathrm{M}$ sodium acetate buffer, $\mathrm{pH} 4.0$, to visualize the glycosaminoglycans, followed by 2 min counterstaining in $0.1 \% \mathrm{w} / \mathrm{v}$ fast green FCF at room temperature (37).

Immunofluorescence. A total of 24 and $72 \mathrm{~h}$ following tMCAO induction, rats were terminally anesthetized by $1.5 \%$ halothane (Shenzhen YunXing Biological Technology Co., Ltd., Shenzhen, China) in air and perfused with saline through the ascending aorta and next with $4 \%$ paraformaldehyde. Neurons cultured in vitro were also subjected to immunofluorescence staining. Sections of terminally anesthetized tMCAO rats were cut (10-20 $\mu \mathrm{m}$ thickness) using a cryomicrotome and incubated with $3 \%$ goat serum (R\&D Systems, Inc., Minneapolis, MN, USA) at $37^{\circ} \mathrm{C}$ for $40 \mathrm{~min}$. Sections were then incubated with rabbit polyclonal primary antibody against RNA binding fox-1 homolog 3 (1:500; cat. no. ab177487; Abcam) or rat polyclonal primary antibody against neuron filament protein (1:500; cat. no. ab4666; Abcam) and Alzheimer-associated neuronal thread protein (1:500; cat. no. ab49385; Abcam) overnight at $4^{\circ} \mathrm{C}$, followed by incubation with secondary antibody (Alexa Fluor 568-donkey anti-mouse immunoglobulin G; 1:1,000; cat. no. ab175700; Abcam) for $2 \mathrm{~h}$ at $25^{\circ} \mathrm{C}$. Subsequently, nuclei were counterstained using DAPI (Abcam) at room temperature for $20 \mathrm{~min}$. The stained sections were examined with a Leica fluorescence microscope (Leica Microsystems $\mathrm{GmbH}$, Wetzlar, Germany) $(38,39)$. The number of rats used for each group was 10 .

Behavioral analysis. The BBB behavior score was used to assess the effect of MDZ on behavior of tMCAO rats (39). Rats were divided into four groups as described above. The assessment was performed at 0,24 and $72 \mathrm{~h}$ following treatment with MDZ. Movement, balance and coordination of limbs, joints, and the whole body of rats was assessed and scored 0-21. Scoring 0-7 points indicated that rats exhibited few or no hindlimb joint movements, $8-14$ points indicated ataxic gait and $15-21$ points indicated that rats could perform fine movements including toe and tail movements.

Statistical analysis. Statistical analysis was performed using SPSS 13.0 software package (SPSS, Inc., Chicago, IL, USA). Results are expressed as the mean \pm standard deviation, and one-way analysis of variance with Dunnett's t-test was used to evaluate significance. $\mathrm{P}<0.05$ was considered to indicate a statistically significant difference.

\section{Results}

$M D Z$ reduces $G L U$-induced neuronal cytotoxicity and apoptosis. To begin, extracted neurons were identified and neuron purity was tested. Neurons were observed under a microscope and were revealed to have normal morphology and clear nerve fiber growth (Fig. 1A). In addition, immunofluorescent staining revealed the purity of the extracted neurons (Fig. 1B). Thus, they were used for further experiments.

Next, the function of GLU in the induction of cytotoxicity and apoptosis was demonstrated in vitro. The change in staining absorbance with or without GLU treatment was measured. The MTT assay results revealed that the number of cells was reduced to $1 / 3$ following GLU treatment (Fig. 1C). Furthermore, LDH release was increased to $257 \%$ compared with the control (Fig. 1D). A significant increase in apoptotic cells following GLU treatment was observed using flow cytometry (Fig. 2A).

Subsequently, the effect of MDZ was evaluated, demonstrating a reduced cytotoxicity and apoptosis in vitro. MDZ reduced neuronal death and $\mathrm{LDH}$ release, and the protective effect was concentration-dependent (Fig. 1C and D), reaching 
A
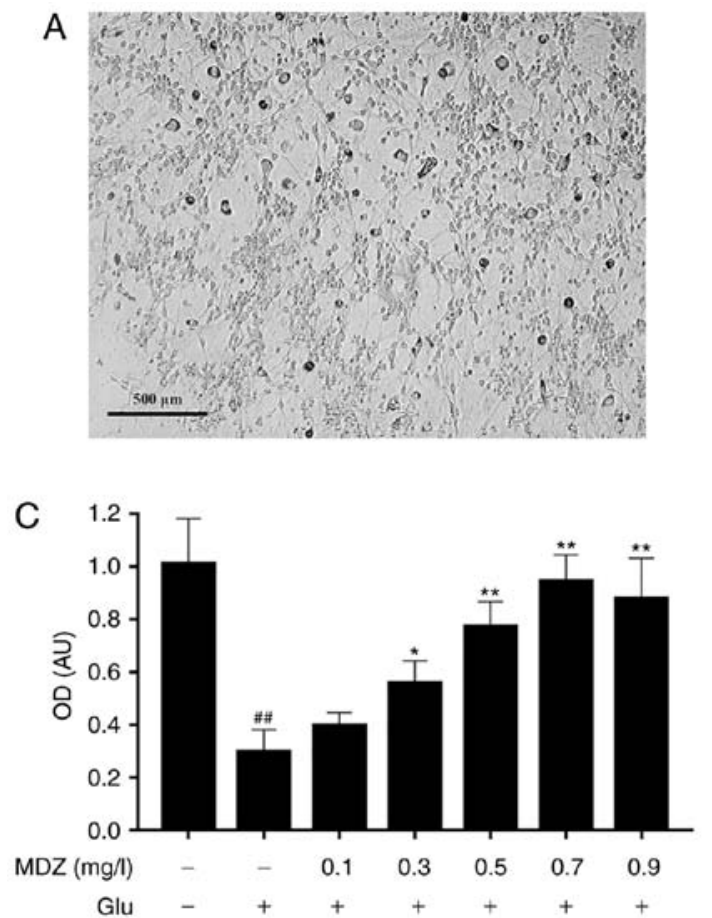

B
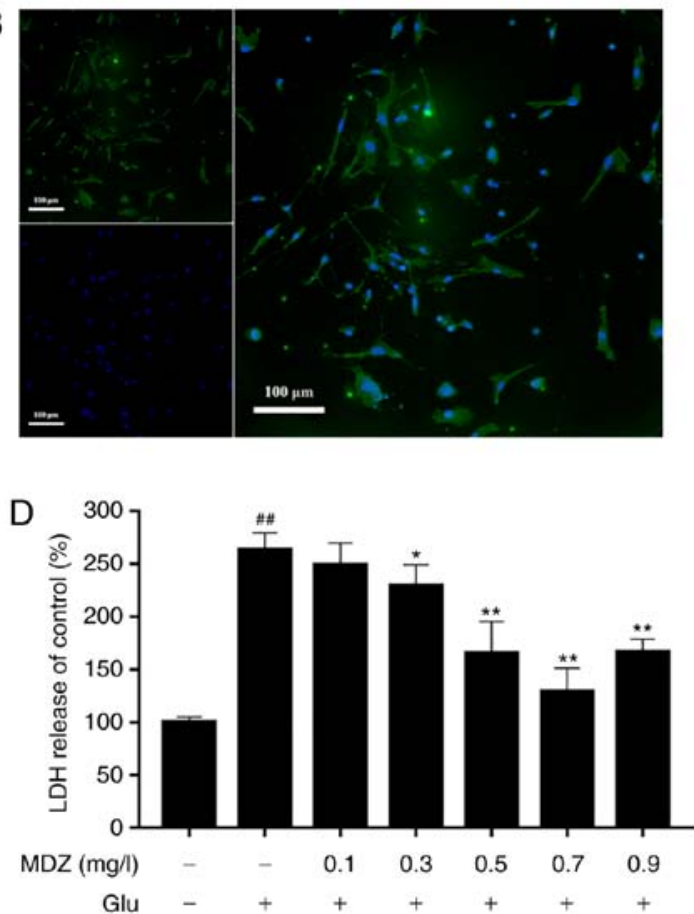

Figure 1. MDZ reduced LDH release. (A) Representative image of neurons obtained from Sprague Dawley rat brain tissue. (B) Immunofluorescent staining was used to examine cell purity. (C) MTT assays were used to detect neuron viability with or without MDZ treatment and $100 \mu$ M GLU. Results are representative of 10 independent experiments. (D) An LDH release assay was performed with or without MDZ treatment and $100 \mu \mathrm{M}$ GLU, to detect the release of LDH. Results are expressed as the mean \pm standard deviation. ${ }^{*} \mathrm{P}<0.05$ and ${ }^{* *} \mathrm{P}<0.01$ vs. MDZ ${ }^{-} \mathrm{Glu}^{+}$group; ${ }^{\# \#} \mathrm{P}<0.01$ vs. control. MDZ, midazolam; LDH, lactate dehydrogenase; GLU, glutamate; OD, optical density.
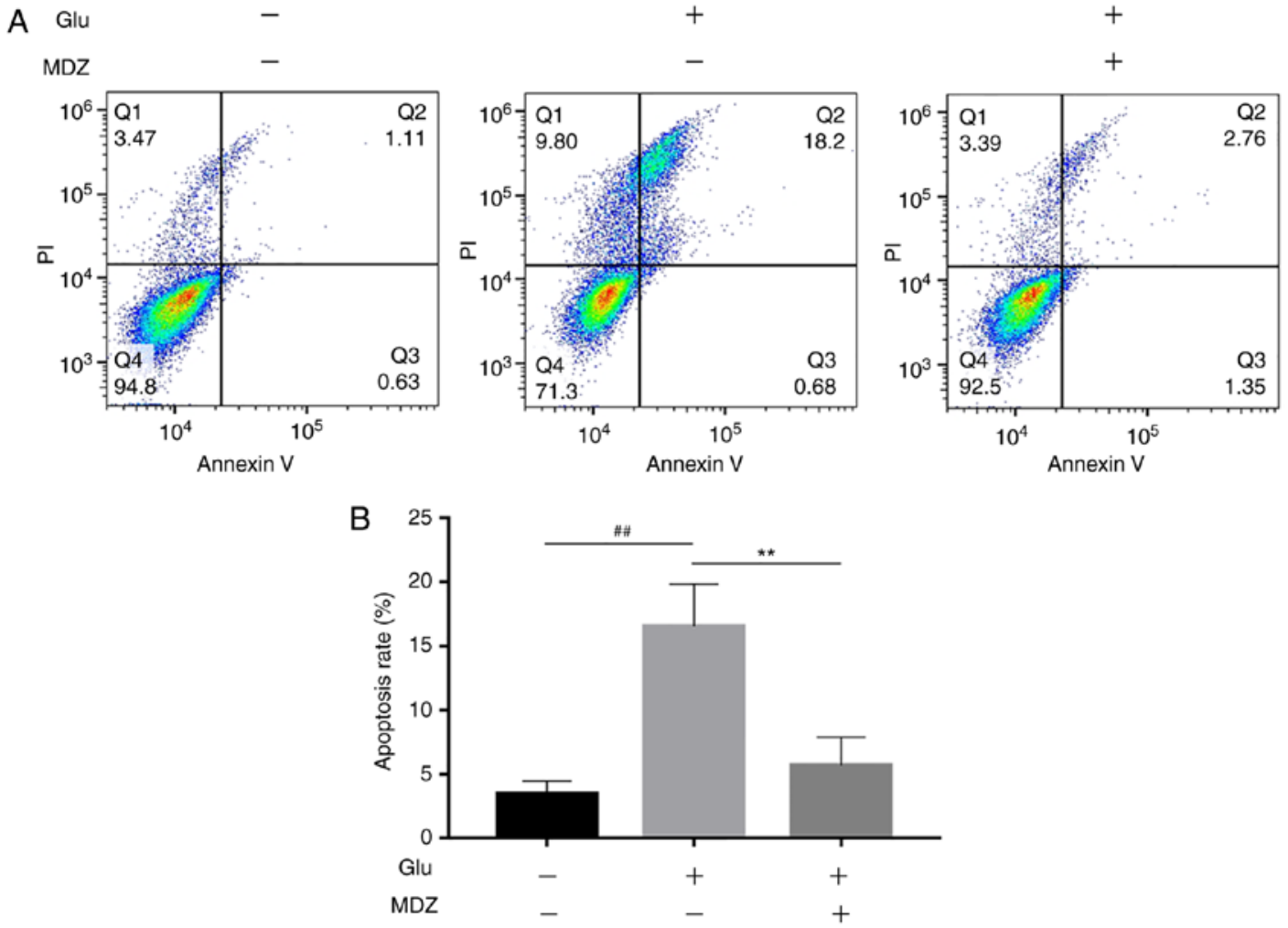

Figure 2. MDZ inhibited neuron apoptosis. (A) Flow cytometry graphs presenting the apoptotic neuron percentage. (B) Bar graph presenting the difference in apoptosis percentage between groups. ${ }^{* *} \mathrm{P}<0.01 \mathrm{MDZ}$ vs. GLU; ${ }^{\# t} \mathrm{P}<0.01$ GLU vs. control. MDZ, midazolam; GLU, glutamate; PI, propidium iodide.

an optimal effect at $0.7 \mathrm{mg} / \mathrm{ml}$. At this concentration, neuron density was close to the density of the control group, with
LDH release of $134 \%$, and was thus considerably reduced compared with group 2. Furthermore, flow cytometry 

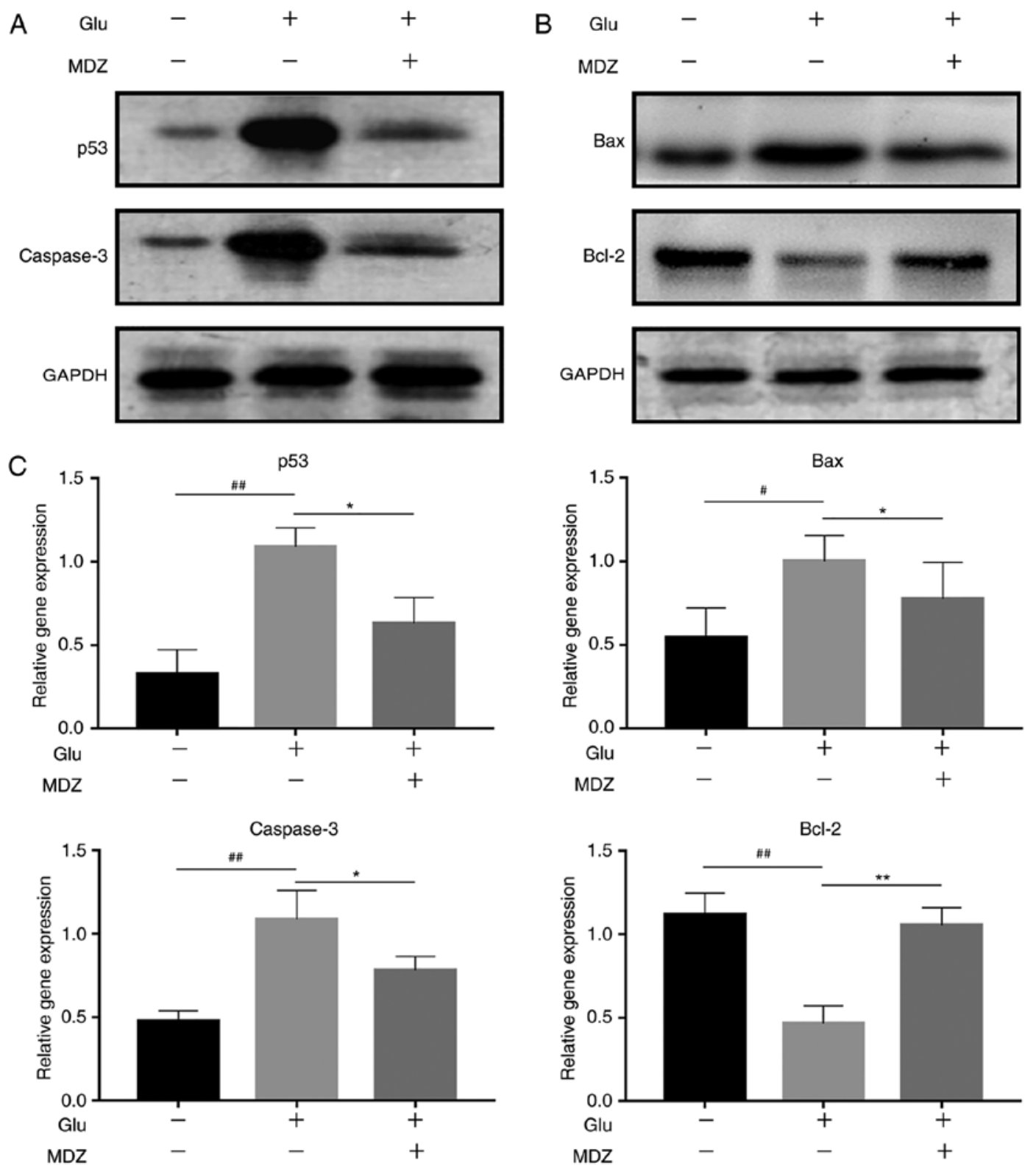

Figure 3. MDZ regulated the expression of apoptosis-associated genes. Western blot analysis of (A) p53 and caspase-3 expression, and (B) Bcl-2 and Bax expression. (C) Semi quantitative reverse transcription polymerase chain reaction analysis of p53, Bax, caspase-3 and Bcl-2 gene expression with or without MDZ treatment. The concentration of MDZ used in these experiments was $0.7 \mathrm{mg} / 1$. Results are expressed as the mean \pm standard deviation. ${ }^{*} \mathrm{P}<0.05$ and ${ }^{* *} \mathrm{P}<0.01$ vs. GLU group; ${ }^{\#} \mathrm{P}<0.05$ and ${ }^{\# /} \mathrm{P}<0.01$ vs. control. MDZ, midazolam; Bcl-2, B cell lymphoma-2; Bax, BCL2 associated $\mathrm{X}$, apoptosis regulator.

results revealed that the effect of MDZ on apoptosis (Fig. 2) was also significant, since GLU increased apoptosis from 3.8 to $16.9 \%$, but apoptosis was reduced to $\sim 5.8 \%$ following MDZ addition.

MDZ protects against GLU-induced changes in apoptosisassociated gene expression. Next, the anti-apoptotic mechanism of MDZ treatment was investigated. p53 and caspase 3 protein expression were noticeably increased following GLU treatment, which may increase cell apoptosis, and the expression of these proteins was significantly inhibited following MDZ treatment (Fig. 3A). Furthermore, $B C L-2$ gene expression was inhibited, and the expression of the apoptosis promoter gene Bax was increased following GLU treatment. MDZ also inhibited this effect (Fig. 3B). The PCR results confirmed the western blotting results, and the difference in the expression of apoptosis-associated genes between experimental groups was statistically significant ( $\mathrm{P}<0.05$; Fig. $3 \mathrm{C}$ ). Therefore, GLU induced the expression of $\mathrm{p} 53$, caspase- 3 and Bax, and inhibited Bcl-2 expression, while MDZ treatment reversed these effects.

$M D Z$ reduces $L D H$ release from brain tissue into the serum. Clinical use of MDZ primarily occurs through peripheral intravenous injection, since MDZ passes through the blood-brain barrier to exert its effects relatively quickly. The involvement of MDZ in the reduction of cytotoxicity in peripheral blood vessels or brain tissue was confirmed by animal experiments. LDH concentrations in the peripheral plasma and brain tissue were measured in different tMCAO experimental animal groups. The results revealed that serum LDH concentration in the tMCAO animal model significantly increased from $502 \pm 24$ 

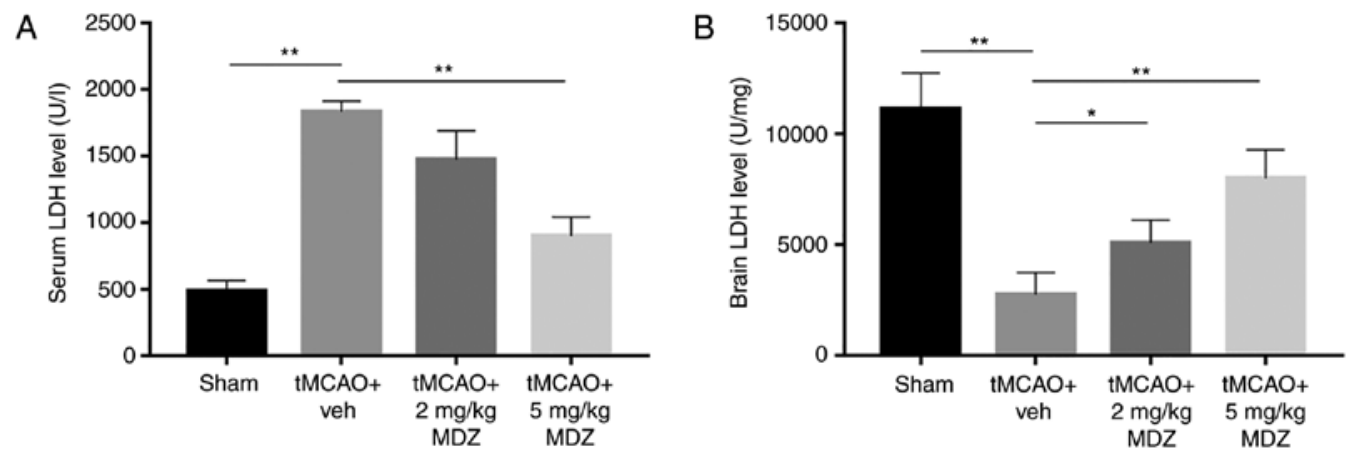

Figure 4. MDZ reduced LDH release into serum from brain tissue. (A) LDH serum levels and (B) brain LDH levels were detected in the sham and tMCAO groups. The concentration of MDZ used in these experiments was $0.7 \mathrm{mg} / 1$. Results are expressed as mean \pm standard deviation. ${ }^{*} \mathrm{P}<0.05$ and ${ }^{* *} \mathrm{P}<0.01$, with comparisons indicated by lines. MDZ, midazolam; LDH, lactate dehydrogenase; tMCAO, transient middle cerebral artery occlusion; Veh, vehicle.

to $1,866 \pm 71 \mathrm{U} / 1$, and decreased following MDZ treatment in a dose-dependent manner (Fig. 4A). LDH concentration in the brain tissue decreased from $11,073 \pm 1,631$ to $2,337 \pm 276 \mathrm{U} / 1$ in the tMCAO animal model, and increased with MDZ treatment in a dose-dependent manner (Fig. 4B).

$M D Z$ protects neurons from $T M C A O$ damage in the ischemic core and boundary zone. TTC staining in rat brain tissue revealed that the tMCAO experimental animal model was successfully constructed in the present study, as demonstrated by the ischemic and boundary areas in rat brain tissue, which were consistent with the physiological characteristics of cerebral infarction (Fig. 5A). After 24 and $72 \mathrm{~h}$, the brain of the corresponding treated animals was subjected to morphological analysis and histological staining. The results of toluidine blue staining revealed that the number of neuron in the tMCAO experimental animals was decreased compared with the Sham group, but was increased following MDZ treatment compared with the tMCAO + vehicle group, in a dose-dependent manner (Fig. 5B). Immunofluorescent staining showed similar results: tMCAO produced a remarkable neuronal damage, while MDZ could significantly play a role in protecting neurons. Furthermore, $5 \mathrm{mg} / \mathrm{kg}$ achieved improved results compared with $2 \mathrm{mg} / \mathrm{kg} \mathrm{MDZ} \mathrm{(Fig.} \mathrm{5C).}$ Furthermore, the staining results revealed that this effect occurred in the boundary core. The number of neurons in the boundary core also increased under MDZ treatment. At 24 and $72 \mathrm{~h}$, neuron density in the ischemic and boundary areas was statistically analyzed. The results revealed a clear increase in cell density following MDZ treatment compared with the tMCAO, although this density was not considerably different between 24 and $72 \mathrm{~h}$ (Fig. 5D and E). In the ischemic core, cell density was decreased from $1.08 \pm 0.11 \times 10^{3}$ to $0.31 \pm 0.03 \times 10^{3}$ cells $/ \mathrm{mm}^{2}$ in $\mathrm{tMCAO}$ rats treated with the vehicle, and increased to $0.74 \pm 0.08 \times 10^{3}$ cells $/ \mathrm{mm}^{2}$ following $5 \mathrm{mg} / \mathrm{kg}$ MDZ treatment within $24 \mathrm{~h}$. Furthermore, in the boundary zone, MDZ achieved a similar effect; increasing cell density from $0.42 \pm 0.02 \times 10^{3}$ to $0.83 \pm 0.08 \times 10^{3}$ cells $/ \mathrm{mm}^{2}$. The behavior of tMCAO rats was also analyzed. The BBB method was used to assess rats' behavior, including movement, coordination and fine movement of the hind limbs. The rats in the control group and sham group were all given a score of 21. Following tMCAO operation all rats were assessed at 7-10. A total of 3 rats were assessed 12-14 following $24 \mathrm{~h}$ of treatment with MDZ (2 mg/kg) and only one of them scored 17 following $72 \mathrm{~h}$ of treatment with MDZ ( $2 \mathrm{mg} / \mathrm{kg})$. In addition, in the MDZ $(5 \mathrm{mg} / \mathrm{kg})$ group only two rats scored 16 at $24 \mathrm{~h}$ and 17 and 18 at $72 \mathrm{~h}$ following treatment with MDZ (data not shown). The results indicate that BBB scores of behaviors improved in certain rats, but not all following treatment with MDZ.

\section{Discussion}

Apoptosis is not only the main pathological change following ischemic cerebral infarction, but is also the main cause of poor prognosis. Cytotoxicity mediated by cytotoxic factors also damage neurons to a certain extent. However, there is no effective anti-apoptotic drug treatment against cerebral infarction currently being used in clinical practice (41). In the present study, the involvement of MDZ in the regulation of apoptosis was investigated in an attempt to identify an optimal dose.

The results revealed that MDZ protected rat cortical neurons from GLU-induced tMCAO models leading to neuronal damage. This protective effect was achieved by inhibiting apoptosis and reducing LDH release. LDH levels in the serum and brain tissue reflected the rapid release of LDH from neurons and released from the brain tissue into the peripheral plasma to mediate cytotoxicity. MDZ inhibited the release of LDH and simultaneously reduced its release from the brain tissue to the peripheral plasma to inhibit cytotoxicity. Reducing Bcl-2 activity and increasing the expression of p53, caspase-3 and Bax are potential mechanisms to regulate apoptosis. As aforementioned, GLU oxidative toxicity serves a key function in the development and progression of neuronal death induced by cerebral ischemia. MDZ has previously been demonstrated to inhibit the apoptosis of astrocytes (20). Consistent with previous studies, the results of the present study suggested that MDZ increased Bcl-2 activation and inhibited apoptosis by decreasing the expression of p53, caspase- 3 and Bax. In addition, MDZ inhibited LDH release to reduce cytotoxicity and apoptosis. MDZ treatment in the tMCAO model also reduced neuronal damage.

The results of the present study did not show a significant difference between 24 and $72 \mathrm{~h}$, suggesting that MDZ had a rapid and prolonged neuroprotective effect. In other words, MDZ achieved its effect within $24 \mathrm{~h}$, protecting neurons by reducing the cytotoxic effect and apoptosis, and 
A

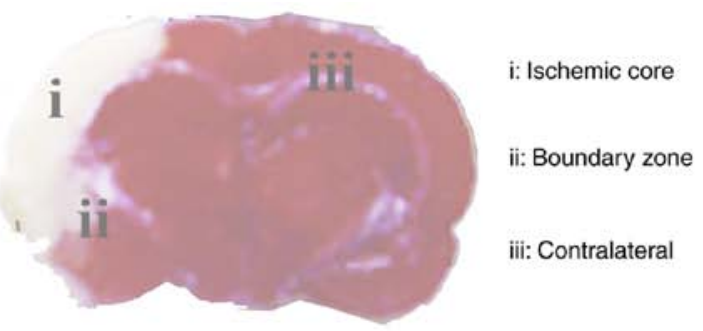

B
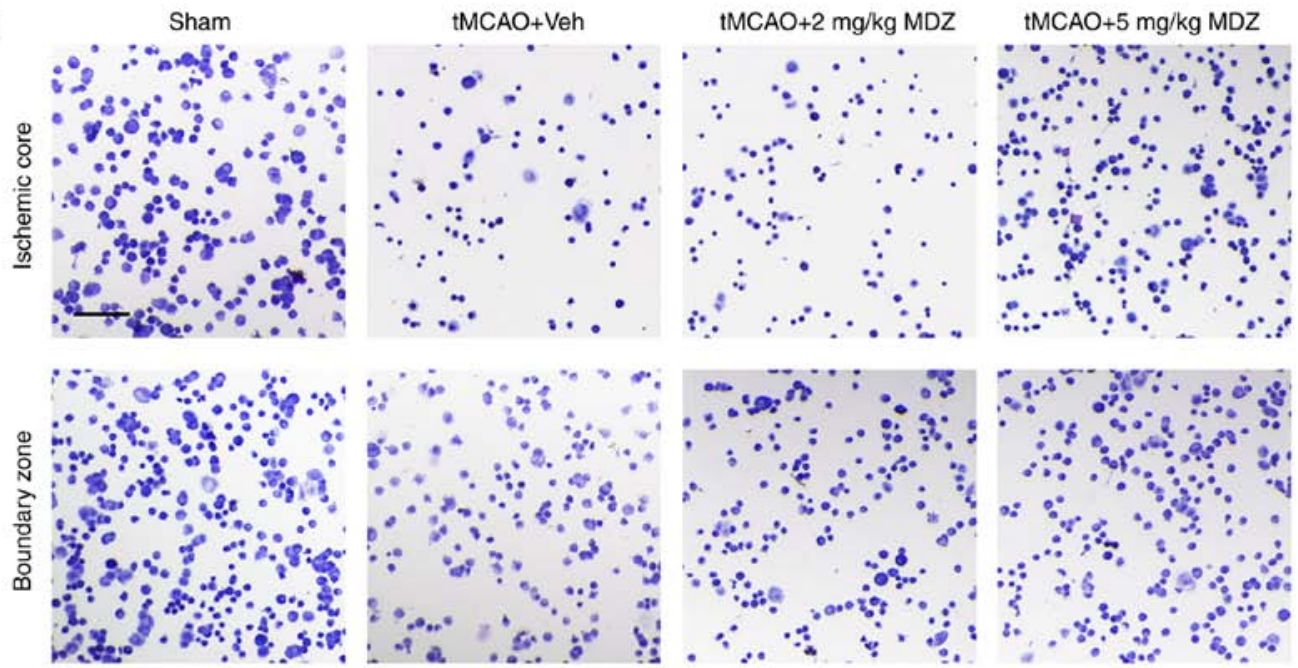

C
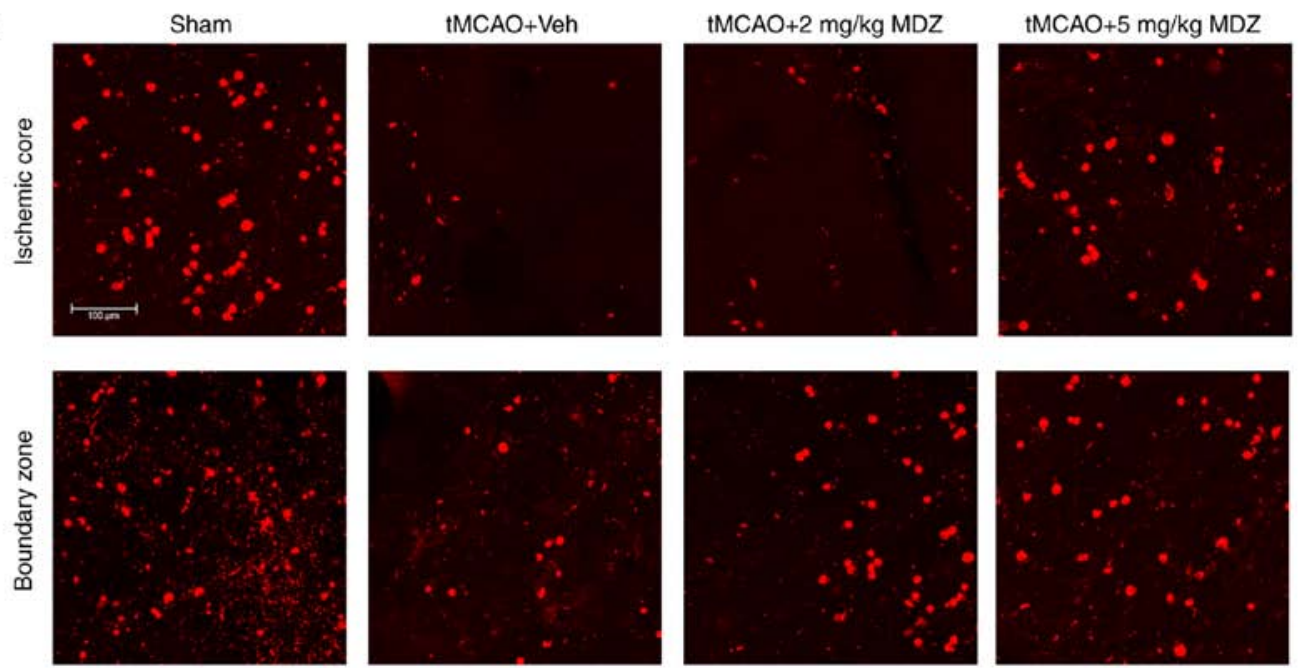

Figure 5. MDZ protected neurons from tMCAO damage. (A) Tetrazolium chloride staining was used to evaluate cerebral infarction pattern. The representative image depicts i) the unstained ischemic core; ii) the boundary core and iii) contralateral. (B) Toluidine blue staining for neuron density in the different experimental groups. Scale bar=100 $\mu \mathrm{m}$. (C) Immunofluorescent staining revealed similar results to the toluidine blue staining. Scale bar=100 $\mu \mathrm{m}$.

this effect increased with MDZ concentration. The ability of MDZ to rapidly cross the blood-brain barrier results in a rapid response to treatment, fewer contraindications and no withdrawal symptoms, providing a foundation for the clinical application against cerebral infarction (41). The present study also investigated the optimum MDZ concentration in vitro, and demonstrated that MDZ achieved optimal neuroprotective effects at $0.7 \mathrm{mg} / \mathrm{l}$. However, the ideal administration route and dose to achieve a local $0.7 \mathrm{mg} / \mathrm{l}$ concentration in the brain requires further study.

The present study demonstrated that the neuroprotective function of MDZ was achieved by reducing LDH release and regulating the expression of apoptosis-associated genes. The inhibition of astrocyte apoptosis due to oxidative glucose deprivation has been demonstrated to be associated with the Janus kinase 2-signaling transducer and activator of transcription 3 signaling pathway (20). However, this aspect was not analyzed in the present study. In addition, MDZ appeared potentially effective in ameliorating behavioral abnormalities of rats. Therefore, the effect of MDZ on behavioral abnormalities and the mechanisms underlying its inhibition of GLU-induced LDH release and neuronal apoptosis require further study.

In conclusion, MDZ achieves its neuroprotective effects by inhibiting neuronal apoptosis, providing a potential novel treatment for stroke and may improve prognosis. 

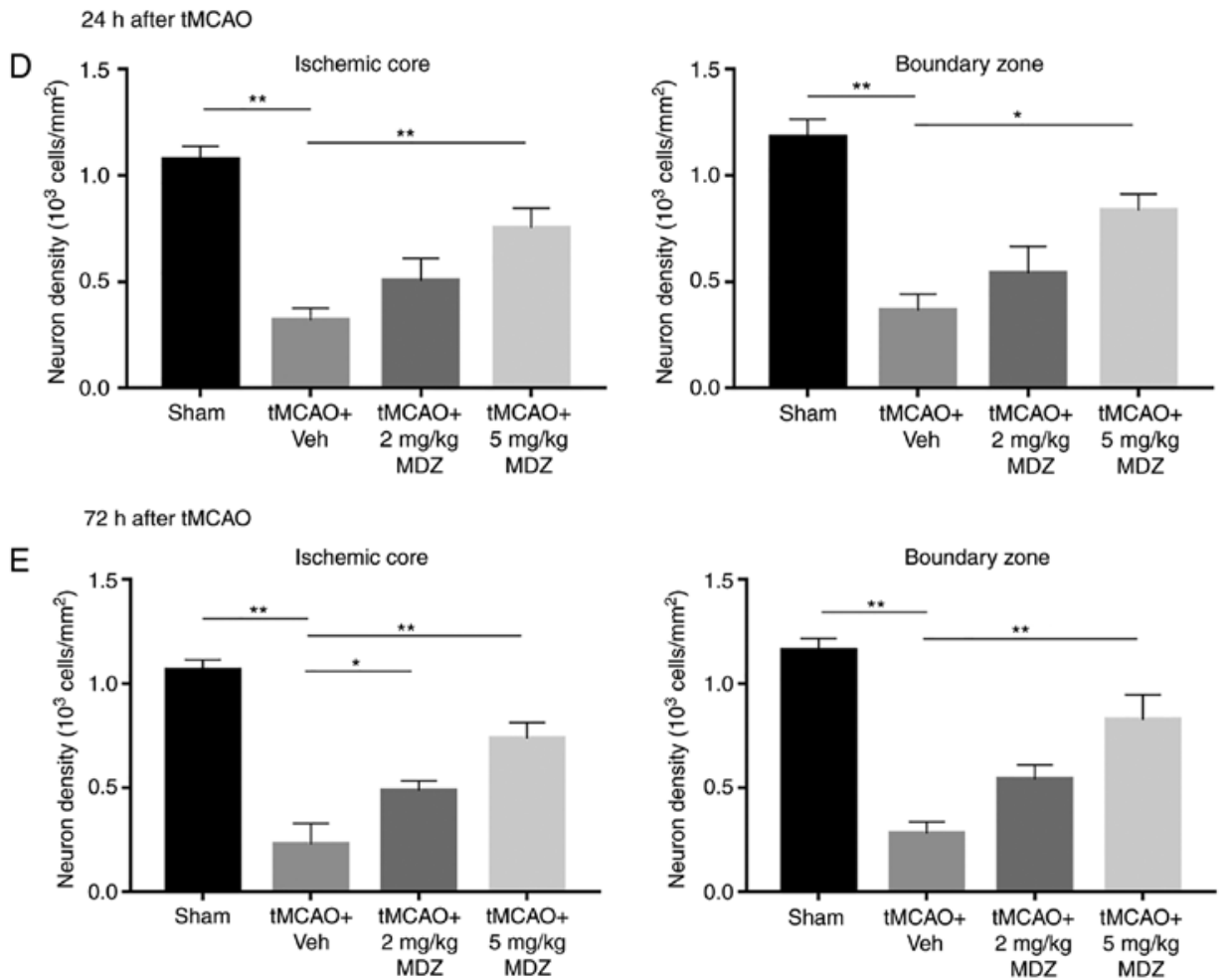

Figure 5. Continued. (D) Neuron density in the ischemic and boundary core after $24 \mathrm{~h}$. (E) Similar results were obtained after $72 \mathrm{~h}$. Results are expressed as the mean \pm standard deviation. ${ }^{*} \mathrm{P}<0.05$ and ${ }^{* *} \mathrm{P}<0.01$, with comparisons indicated by lines. MDZ, midazolam; tMCAO, transient middle cerebral artery occlusion; Veh, vehicle.

\section{Acknowledgements}

Not applicable.

\section{Funding}

The present study was supported by the 2016 Cultivation Fund of Hainan Medical University (grant no. HY2016-07) and the Industry Research Project of Hainan Health and Family Planning Commission (grant no. 1601032054A2001).

\section{Availability of data and materials}

The analyzed data sets generated during the study are available from the corresponding author on reasonable request.

\section{Authors' contributions}

HY took part in all experiments and was the major contributor in writing the manuscript. XW completed the cell experiments and took part in data analysis. FK was responsible for the cell culture and took part in data analysis. ZC helped complete the cell experiments and other experiments in vivo. YM took part in animal experiments and manuscript writing. MD was in charge of the overall planning and gave substantial advice for experiments and manuscript. All authors read and approved the final manuscript.

\section{Ethics approval and consent to participate}

All animal procedures followed the Guide for the Care and Use of Laboratory Animals and were approved by the Institutional Clinical Experiments Committee of the Second Affiliated Hospital of Hainan Medical University (Haikou, China).

\section{Patient consent for publication}

Not applicable.

\section{Competing interests}

The authors declare that they have no competing interests.

\section{References}

1. Shichita T, Ito M, Morita R, Komai K, Noguchi Y, Ooboshi H, Koshida R, Takahashi S, Kodama T and Yoshimura A: MAFB prevents excess inflammation after ischemic stroke by accelerating clearance of damage signals through MSR1. Nat Med 23: 723-732, 2017.

2. Amarenco P, Albers GW, Denison H, Easton JD, Evans SR, Held P, Hill MD, Jonasson J, Kasner SE, Ladenvall P, et al: Efficacy and safety of ticagrelor versus aspirin in acute stroke or transient ischaemic attack of atherosclerotic origin: A subgroup analysis of SOCRATES, a randomised, double-blind, controlled trial. Lancet Neurol 16: 301-310, 2017.

3. Compter A, van der Worp HB, Schonewille WJ, Vos JA, Boiten J, Nederkoorn PJ, Uyttenboogaart M,Lo RT, Algra A and Kappelle LJ; VAST investigators: Stenting versus medical treatment in patients with symptomatic vertebral artery stenosis: A randomised open-label phase 2 trial. Lancet Neurol 14: 606-614, 2015.

4. Chen Y, Won SJ, Xu Y and Swanson RA: Targeting microglial activation in stroke therapy: Pharmacological tools and gender effects. Curr Med Chem 21: 2146-2155, 2014.

5. Kravchick DO, Karpova A, Hrdinka M, Lopez-Rojas J, Iacobas S, Carbonell AU, Iacobas DA, Kreutz MR and Jordan BA: Synaptonuclear messenger PRR7 inhibits c-Jun ubiquitination and regulates NMDA-mediated excitotoxicity. EMBO J 35: 1923-1934, 2016 
6. Stonesifer C, Corey S, Ghanekar S, Diamandis Z, Acosta SA and Borlongan CV: Stem cell therapy for abrogating stroke-induced neuroinflammation and relevant secondary cell death mechanisms. Prog Neurobiol 158: 94-131, 2017.

7. Shuros AC, Salo RW, Florea VG, Pastore J, Kuskowski MA, Chandrashekhar Y and Anand IS: Ventricular preexcitation modulates strain and attenuates cardiac remodeling in a swine model of myocardial infarction. Circulation 116: 1162-1169, 2007.

8. Sun F, Li X, Duan WQ, Tian W, Gao M, Yang J, Wu XY, Huang D, $\mathrm{Xia} \mathrm{W}$, Han YN, et al: Transforming growth factor- $\beta$ receptor III is a potential regulator of ischemia-induced cardiomyocyte apoptosis. J Am Heart Assoc 6: pii:e005357, 2017.

9. Wang $\mathrm{C}$ and Youle RJ: Predominant requirement of Bax for apoptosis in HCT116 cells is determined by Mcl-1's inhibitory effect on Bak. Oncogene 31: 3177-3189, 2012.

10. Arlet JB, Ribeil JA, Guillem F, Negre O, Hazoume A, Marcion G, Beuzard Y, Dussiot M, Moura IC, Demarest S, et al: HSP70 sequestration by free $\alpha$-globin promotes ineffective erythropoiesis in $\beta$-thalassaemia. Nature 514: 242-246, 2014

11. Li H, Lv B, Kong L, Xia J, Zhu M, Hu L, Zhen D, Wu Y, Jia X, Zhu S and Cui $\mathrm{H}$ : Nova1 mediates resistance of rat pheochromocytoma cells to hypoxia-induced apoptosis via the $\mathrm{Bax} / \mathrm{Bcl}-2 /$ caspase-3 pathway. Int J Mol Med 40: 1125-1133, 2017

12. Mathieu J, Zhou W, Xing Y, Sperber H, Ferreccio A, Agoston Z, Kuppusamy KT, Moon RT and Ruohola-Baker H: Hypoxia-inducible factors have distinct and stage-specific roles during reprogramming of human cells to pluripotency. Cell Stem Cell 14: 592-605, 2014

13. Llambi F, Wang YM, Victor B, Yang M, Schneider DM, Gingras S, Parsons MJ, Zheng JH, Brown SA, Pelletier S, et al: BOK is a non-canonical BCL-2 family effector of apoptosis regulated by ER-associated degradation. Cell 165: 421-433, 2016

14. Grinkevich VV, Nikulenkov F, Shi Y, Enge M, Bao W, Maljukova A, Gluch A, Kel A, Sangfelt O and Selivanova G: Ablation of key oncogenic pathways by RITA-reactivated p53 is required for efficient apoptosis. Cancer Cell 31: 724-726, 2017.

15. Andrabi SA, Kang HC, Haince JF, Lee YI, Zhang J, Chi Z, West AB, Koehler RC, Poirier GG, Dawson TM and Dawson VL: Iduna protects the brain from glutamate excitotoxicity and stroke by interfering with poly(ADP-ribose) polymer-induced cell death. Nat Med 17: 692-699, 2011.

16. Weber NC, Riedemann I, Smit KF, Zitta K, van de Vondervoort D, Zuurbier CJ, Hollmann MW, Preckel B and Albrecht M: Plasma from human volunteers subjected to remote ischemic preconditioning protects human endothelial cells from hypoxia-induced cell damage. Basic Res Cardiol 110: 17, 2015.

17. Drake-Brockman TF, Ramgolam A, Zhang G, Hall GL and von Ungern-Sternberg BS: The effect of endotracheal tubes versus laryngeal mask airways on perioperative respiratory adverse events in infants: A randomised controlled trial. Lancet 389: 701-708, 2017.

18. Scott RC: Buccal midazolam as rescue therapy for acute seizures. Lancet Neurol 4: 592-593, 2005.

19. Osterop SF, Virtanen MA, Loepke JR, Joseph B, Loepke AW and Vutskits L: Developmental stage-dependent impact of midazolam on calbindin, calretinin and parvalbumin expression in the immature rat medial prefrontal cortex during the brain growth spurt. Int J Dev Neurosci 45: 19-28, 2015.

20. Liu L, You Q, Tu Y, Li Q, Zheng L, Li X, Gu J and Wang G: Midazolam inhibits the apoptosis of astrocytes induced by oxygen glucose deprivation via targeting JAK2-STAT3 signaling pathway. Cell Physiol Biochem 35: 126-136, 2015.

21. Makinodan M, Rosen KM, Ito S and Corfas G: A critical period for social experience-dependent oligodendrocyte maturation and myelination. Science 337: 1357-1360, 2012.

22. Marion E, Song OR, Christophe T, Babonneau J, Fenistein D Eyer J, Letournel F, Henrion D, Clere N, Paille V, et al: Mycobacterial toxin induces analgesia in buruli ulcer by targeting the angiotensin pathways. Cell 157: 1565-1576, 2014.

23. Novoa-Herran S, Umaña-Perez A, Canals F and Sanchez-Gomez M: Serum depletion induces changes in protein expression in the trophoblast-derived cell line HTR-8/SVneo. Cell Mol Biol Lett 21: 22, 2016.

24. Zou ZK, Huang YQ, Zou Y, Zheng XK and Ma XD: Silencing of LSD1 gene modulates histone methylation and acetylation and induces the apoptosis of JeKo-1 and MOLT-4 cells. Int J Mol Med 40: 319-328, 2017.
25. Chaudhari U, Nemade H, Gaspar JA, Hescheler J, Hengstler JG and Sachinidis A: MicroRNAs as early toxicity signatures of doxorubicin in human-induced pluripotent stem cell-derived cardiomyocytes. Arch Toxicol 90: 3087-3098, 2016.

26. Kumamaru H, Ohkawa Y, Saiwai H, Yamada H, Kubota K, Kobayakawa K, Akashi K, Okano H, Iwamoto Y and Okada S: Direct isolation and RNA-seq reveal environment-dependent properties of engrafted neural stem/progenitor cells. Nat Commun 3: 1140, 2012 .

27. Huang WH, Liao WR and Sun RX: Astragalus polysaccharide induces the apoptosis of human hepatocellular carcinoma cells by decreasing the expression of Notch1. Int J Mol Med 38: 551-557, 2016.

28. Zhang SJ, Xu TT, Li L, Xu YM, Qu ZL, Wang XC, Huang SQ, Luo Y, Luo NC, Lu P, et al: Bushen-Yizhi formula ameliorates cognitive dysfunction through SIRT1/ER stress pathway in SAMP8 mice. Oncotarget 8: 49338-49350, 2017.

29. Yu Z, Rayile A, Zhang X, Li Y and Zhao Q: Ulinastatin protects against lipopolysaccharide-induced cardiac microvascular endothelial cell dysfunction via downregulation of lncRNA MALAT1 and EZH2 in sepsis. Int J Mol Med 39: 1269-1276, 2017.

30. Starokadomskyy P, Gemelli T, Rios JJ, Xing C, Wang RC, Li H, Pokatayev V, Dozmorov I, Khan S, Miyata N, et al: DNA polymerase- $\alpha$ regulates the activation of type I interferons through cytosolic RNA:DNA synthesis. Nat Immunol 17: 495-504, 2016.

31. Zhang XD, Baladandayuthapani V, Lin H, Mulligan G, Li B, Esseltine DL, Qi L, Xu J, Hunziker W, Barlogie B, et al: Tight junction protein 1 modulates proteasome capacity and proteasome inhibitor sensitivity in multiple myeloma via EGFR/JAK1/STAT3 signaling. Cancer Cell 29: 639-652, 2016.

32. Shen Z, Zheng Y, Wu J, Chen Y, Wu X, Zhou Y, Yuan Y, Lu S, Jiang L, Qin Z, et al: PARK2-dependent mitophagy induced by acidic postconditioning protects against focal cerebral ischemia and extends the reperfusion window. Autophagy 13: 473-485, 2017.

33. National Research Council (US) Institute for Laboratory Animal Research: Guide for the Care and Use of Laboratory Animals. National Academies Press (US), Washington, DC, 1996.

34. Chen B, Tao J, Lin Y, Lin R, Liu W and Chen L: Electroacupuncture exerts beneficial effects against cerebral ischemia and promotes the proliferation of neural progenitor cells in the cortical peri-infarct area through the $\mathrm{Wnt} / \beta$-catenin signaling pathway. Int J Mol Med 36: 1215-1222, 2015.

35. van Hout GP, Bosch L, Ellenbroek GH, de Haan JJ, van Solinge WW, Cooper MA, Arslan F, de Jager SC, Robertson AA, Pasterkamp G and Hoefer IE: The selective NLRP3-inflammasome inhibitor MCC950 reduces infarct size and preserves cardiac function in a pig model of myocardial infarction. Eur Heart J 38: 828-836, 2017.

36. Alvarez-Saavedra M, De Repentigny Y, Lagali PS, Raghu Ram EV, Yan K, Hashem E, Ivanochko D, Huh MS, Yang D, Mears AJ, et al: Snf2h-mediated chromatin organization and histone $\mathrm{H} 1$ dynamics govern cerebellar morphogenesis and neural maturation. Nat Commun 5: 4181, 2014

37. Kaminski MM, Tosic J, Kresbach C, Engel H, Klockenbusch J, Müller AL, Pichler R, Grahammer F, Kretz O, Huber TB, et al: Direct reprogramming of fibroblasts into renal tubular epithelial cells by defined transcription factors. Nat Cell Biol 18: 1269-1280, 2016

38. Lee JS, Chang EH, Koo OJ, Jwa DH, Mo WM, Kwak G, Moon HW, Park HT, Hong YB and Choi BO: Pmp22 mutant allele-specific siRNA alleviates demyelinating neuropathic phenotype in vivo. Neurobiol Dis 100: 99-107, 2017.

39. Wang H, Li P, Xu N, Zhu L, Cai M, Yu W and Gao Y: Paradigms and mechanisms of inhalational anesthetics mediated neuroprotection against cerebral ischemic stroke. Med Gas Res 6: 194-205, 2016.

40. Basso DM, Beattie MS and Bresnahan JC: A sensitive and reliable locomotor rating scale for open field testing in rats. J Neurotrauma 12: 1-21, 1995.

41. Matsuo N and Morita T: Efficacy, safety, and cost effectiveness of intravenous midazolam and flunitrazepam for primary insomnia in terminally ill patients with cancer: A retrospective multicenter audit study. J Palliat Med 10: 1054-1062, 2007. 